\title{
原子間力顕微鏡および小角 $\mathrm{X}$ 線散乱による セルロース䋊維の表面構造解析 ${ }^{\dagger}$
}

\author{
巽大輔* 田結庄 義 博** 松 本 孝 芳* \\ Analysis of the Surface Structure of Cellulose Fibers \\ Using Atomic Force Microscopy and Small-Angle X-Ray Scattering
}

by

Daisuke TATSumi ${ }^{*}$, Yoshihiro TAInosho ${ }^{* *}$ and Takayoshi Matsumoto ${ }^{*}$

\begin{abstract}
The surface images of softwood pulp fibers were investigated with an atomic force microscope (AFM). Microfibril-like structures were observed on the fibers. Periodic domains were observed on the fibrils, and they lay in a row at every $70 \mathrm{~nm}$. The surface structures were discussed in terms of the autocorrelation function calculated from the AFM images. The correlation length, $\xi$, obtained from the function was $70 \mathrm{~nm}$. This value corresponds to that directly confirmed in the original AFM images. The autocorrelation function can be converted into the power spectral density (PSD). The PSD decayed versus the absolute value of wave number vector, $k$, according to a power-law. The exponent value was-2, which indicates that no fractal structures exist on the fiber surface. The other power-law decay was observed for the small-angle x-ray scattering (SAXS) intensity of the fiber. The intensity followed Porod's inverse fourth power law. These two results indicate that the surface structure of the fiber is definitely bordered. The coincidence of the two different analyses implies that the PSD obtained from the AFM images can be interpreted as a scattering image of surface under the ambient condition.
\end{abstract}

Key words : Atomic force microscopy (AFM), Autocorrelation, Fourier analysis, Fractal dimensions, Microfibrils, Periodic variations, Surface structure, X-ray diffraction

\section{1 緒}

近年，環境にやさしい高分子材料としてセルロースが 再び注目されてきている，セルロースを材料として用い る場合は，それが天然で生産されるままの状態で扱われ ることも多い. したがって, その固有の繊維形状が製品 の物性を大きく左右する。 とくに，七ルロース表面の微 細構造は, 繊維の表面改質や紙の繊維間結合を理解する うえでも非常に重要な因子である.

セルロース繊維の表面構造に関する研究は, 主に各種 顕微鏡による観察，とりわけ最近では原子間力顕微鏡 $(\mathrm{AFM})$ 観察によって行われてきた. ${ }^{1) \sim 49}$ 顕微鏡による直 接観察は直感的にも理解しやすく非常に有効な手段であ るが, 定量性の点では劣る。しかし, 定量性に優れた構 造解析手段である波動の散乱現象を利用する方法は, 得 られた散乱像と元の実空間像を対応させるのが困難であ るうえ, 表面の構造解析に対してはこれまでほとんど適 用されてこなかった。

実空間像と散乱像は Fourier 変換によって相互に変換 できることが知られている.すなわち, 顕微鏡観察によ って得られた像を波数空間に変換すれば, 従来の散乱法 によって得られる情報と同等の情報が得られ，構造の中 に潜む周期性や秩序性を定量化できる.

そこで本研究では，まず天然セルロース繊維表面の微
細構造を AFM を用いて観察した. 次に, 得られた像の 情報を定量化するために, AFM 像の自己相関関数を求 め, これを Fourier 変換して纎維表面の凹凸に関するパ ワースペクトル密度関数 (PSD) を得た. PSD を元の AFM 像と対応させることで，セルロース繊維の表面をナ ノメータースケールで検討した。 さらに, PSD を小角 X 線散乱 (SAXS) 測定の結果と比較し,セルロース繊維表面 のフラクタル性について考察した.

\section{2 実験}

\section{$2 \cdot 1$ 試料}

天然セルロース䋊維として, 日本製紙(株より提供され た針葉樹さらしクラフトパルプを用いた。これを PFI mill で 30000 回転吒解することで, 繊維を柔軟化させ, 繊維 表面にフィブリルを派生させた。 その後, 䋊維は蒸留水 で十分に洗浄し, 水の表面張力の作用で基材に吸着させ た. なお，基材には光学顕微鏡用カバーグラスをエタノ 一ル中で十分に超音波洗浄したものを用いた。

\section{$2 \cdot 2$ AFM 観察}

オリンパス走査型プローブ顕微鏡 NV2000を用いて， Alternative Contacting モードで大気中において観察し た.カンチレバーはオリンパス製 Micro cantilever OMCL-AC240TS-1 ( $\mathrm{Si}$ 単結晶, バネ定数 $2.8 \sim 4.6 \mathrm{Nm}^{-1}$, 先端部の曲率半径は $10 \mathrm{~nm}$ 以下〔值は公称值〕) を用い,

原稿受理 平成 14 年 3 月 11 日 Received Mar. 11, 2002

* 正 会 員 京都大学大学院農学研究科森林科学専攻 于606-8502 京都市左京区北白川追分町, Div. of Forest and Biomaterials Sci., Graduate School of Agriculture, Kyoto Univ., Sakyo-ku, Kyoto, 606-8502

** 京都大学大学院農学研究科 ７606-8502 京都市左京区北白川追分町, Grad. School of Agriculture, Kyoto Univ., Sakyo-ku, Kyoto, 606-8502 
加振周波数を $58 \mathrm{kHz}$, 実効振幅を 50 〜 $80 \mathrm{~nm}$ に設定し た。画像はスキャン速度 $0.5 \mathrm{~Hz}, 512 \times 512$ 画素で取り 込み，傾きの補正を行った。

\section{$2 \cdot 3$ SAXS 測定}

京都大学超強力 $\mathrm{X}$ 線回折実験室の $6 \mathrm{~m}$ 点収束型 $\mathrm{X}$ 線 散乱測定装置 ${ }^{6)}$ を用い, $\mathrm{CuK} \alpha$ 線 $\left(\lambda=1.54 \times 10^{-10} \mathrm{~m}\right)$ を 線源として繊維シートの散乱像を得た. 測定は $25^{\circ} \mathrm{C} て ゙$ 行 い, 得られた 2 次元像は円環平均して 1 次元像とした。

\section{3 結}

果

\section{3・1ＡFM によるセルロース繊維表面の観察}

パルプ䋊維は強度に吒解を受けると, その表面からフ イブリルを派生する。吒解によって派生したフィブリル の AFM 像を Fig. 1 に示す. 䋊維自身を観察するより も，このようにフィブリルを観察する方が, より明膫な 表面の像を得ることができた。

さらに微小な領域を走査して得られた画像に, 陰影を つけた像を Fig. 2A に, 高さを色の浱淡で表した別の部 分における像を Fig. $2 \mathrm{~B}$ に示す.いずれの像にもミクロ フィブリル様の微細繊維が一方向に配向している様子が 明瞭に見られた. Fig. 2 の走査領域は $1 \times 1 \mu \mathrm{m}^{2}$ であるの で, 微細繊維の幅は約 $70 \mathrm{~nm}$ である。その微細繊維の上 に約 70nm の周期で粒状の構造が現れていることがわか つた。

微細繊維の形状をより詳細に観察するために，それが 単独で存在している箇所を走査した。 その像を Fig. 3 に 示す. 微細繊維の幅は Fig. 2 で見られるものと同様, 約 $70 \mathrm{~nm}$ であった。画像中央より左側に見られる微細繊維 は平均の高さが $14 \mathrm{~nm}$ であるが, 左上角においてその高 さが急に $5.8 \mathrm{~nm}$ に減少している。また，画像中央部に非 繊維状物質も観察できた。

\section{3・2 AFIM 像の定量的解析}

得られた像を定量的に解析するために, Fig. 2 を用い て, 式 (1)で定義される自己相関関数 $g(r)$ を算出した. ${ }^{7)}$

$$
g(r)=\left\langle\left(h\left(r_{0}\right)-h_{0}\right)\left(h\left(r_{0}+r\right)-h_{0}\right)\right\rangle_{r 0}
$$

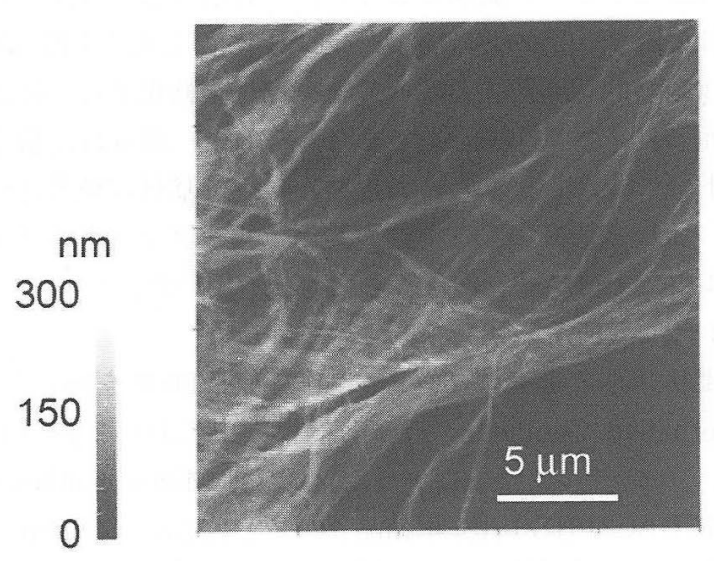

Fig. 1. AFM image of fibrillar material produced by beating of bleached kraft pulp fiber dried down on a glass surface. Scan size was $20 \times 20 \mu \mathrm{m}^{2}$, and the height was indicated by the gray level shown in the color bar.
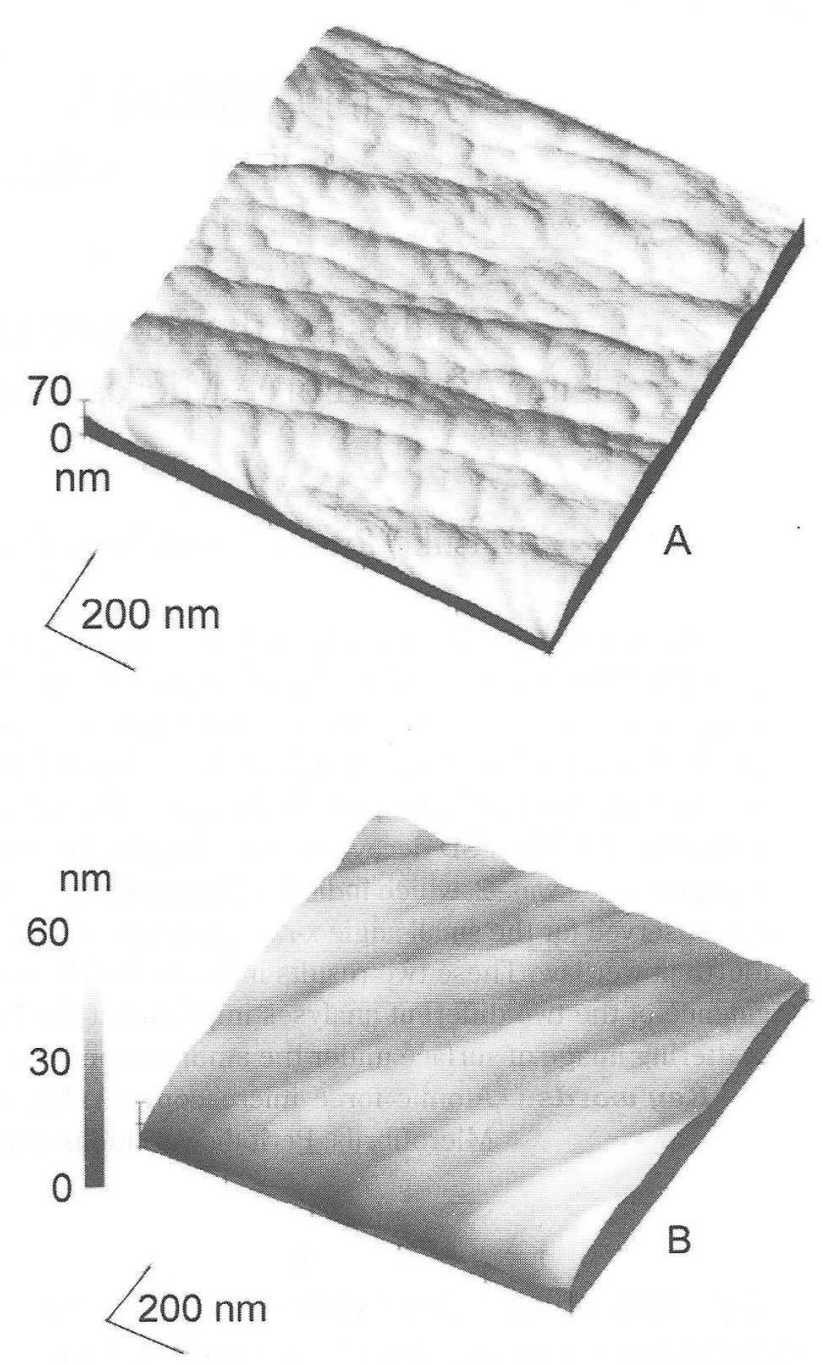

Fig. 2. AFM images of narrower area of the fibrillar material ; (A) shadowed image, (B) another part in which the height was indicated by the gray scale. Scan size was $1 \times 1 \mu \mathrm{m}^{2}$ for both images.

ただし， $h\left(r_{0}\right)$ 打よび $h\left(r_{0}+r\right)$ は，それぞれ位置 $r_{0}$ および $r_{0}+r$ における高さ， $h_{0}$ は平均の高さである.<> 平均を表す。結果を Fig. 4 に示す。図中の A 扎よびB は，それぞれFig. 2のそれと刘応している。一般に自己 相関関数は Gauss 関数で近似される場合が多く, ${ }^{7}$ Fig. 4 のAで表されるプロットもそのような特徴を有している. Aのプロットに関して, Gauss 関数 $g(r)=g(0) \exp$ $\left[-(r / \xi)^{2}\right]$ をイッティングさせると, $\xi=63 \mathrm{~nm}$ が得られ

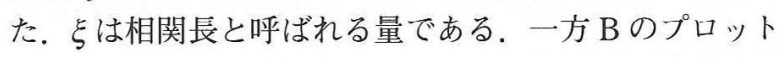
は2つの Gauss 関数の線形結合でフィッティングさせる ことができ，2つの相関長はそれぞれ $\xi_{1}=49 \mathrm{~nm}$ および $\xi_{2}=180 \mathrm{~nm}$ と求められた.

\section{3・3 パワースペクトルおよび SAXS 強度}

次に, $g(r)$ を Fourier 変換してパワースペクトル密度関 数 $P_{\mathrm{PSD}}(k)$ を求めることを試みた. ${ }^{7)} P_{\mathrm{PSD}}(k)$ は次式で表さ れる.

$$
P_{\mathrm{PSD}}(\boldsymbol{k})=|F(\boldsymbol{k})|^{2}=F \cdot F^{*}
$$

ここで, $\boldsymbol{k}$ は波数べタトルである. $F(\boldsymbol{k})$ は $h(\boldsymbol{r})$ の Fourier 変換で, 


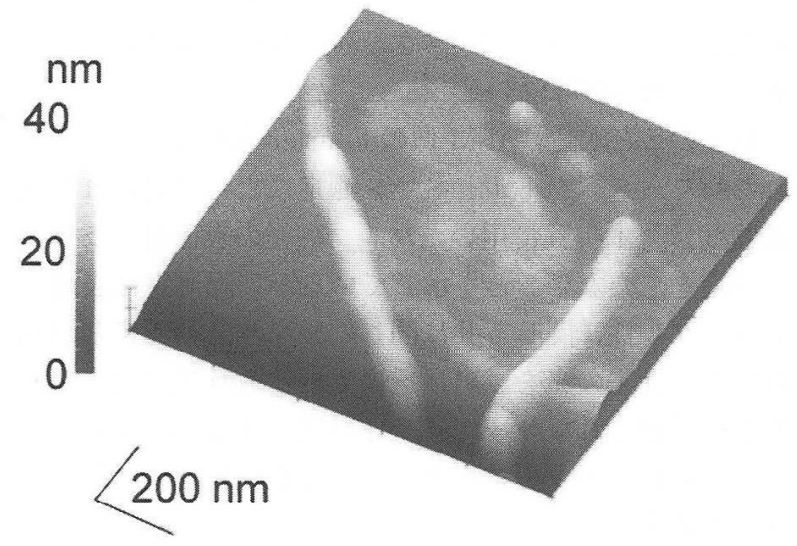

Fig. 3. AFM image of individual fibrillar material. Nonfibrillar material was also observed. Scan size was $1 \times$ $1 \mu \mathrm{m}^{2}$, and the height was indicated by the gray scale.

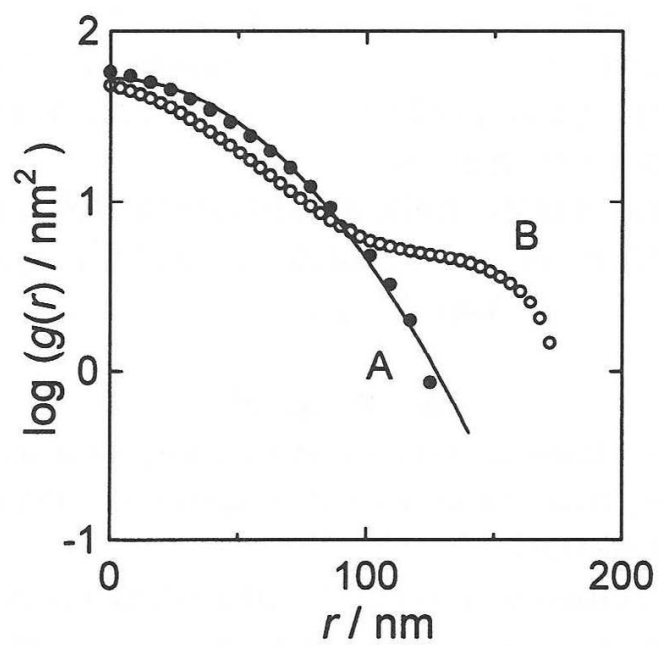

Fig. 4. Autocorrelation function, $g(r)$, of the AFM images in Fig. 2. Legend is the same as shown in Fig. 2. Plots for (A) are fitted by a Gaussian.

$$
F(\boldsymbol{k})=\int_{\mathrm{S}} h(\boldsymbol{r}) \exp (-\mathrm{i} \boldsymbol{k} \cdot \boldsymbol{r}) d \boldsymbol{r}
$$

で表され、コンボリューション定理から，

$$
\begin{aligned}
F \cdot F^{*} & =\int_{S}\left\langle h\left(r_{0}\right) h\left(r_{0}+\boldsymbol{r}\right)\right\rangle_{r 0} \exp (-\mathrm{i} \boldsymbol{k} \cdot \boldsymbol{r}) d \boldsymbol{r} \\
& =\int_{S} g(\boldsymbol{r}) \exp (-\mathrm{i} \boldsymbol{k} \cdot \boldsymbol{r}) d \boldsymbol{r}
\end{aligned}
$$

と表される。式 (2) および(4)より $P_{\mathrm{PSD}}(k)$ は $g(r) の$ Fourier 変換で求められることがわかる. Fig. 4 の $g(r)$ に対して，FFT 法を用いて $P_{\mathrm{PSD}}(k)$ を求めた結果を Fig. 5 に示す．図中のA およびB は，Figs. 2 および 4 のそれと 対応している。図より， $P_{\mathrm{PSD}}(k)$ と $k$ の間にべき乗側が成 り立つことがわかる．Fig. 5 の直線部の勾配より，A，B いずれの場合も，べきの指数は-2であることが示された。

Fig. 6 には繊維シートの SAXS 測定によって得られた, 散乱強度 $I(q)$ と散乱べタトルの大きさ $q\left(=4 \pi \lambda{ }^{1} \sin \right.$ $(\theta / 2))$ の関係を示す。図からわかるように, 空間スケー ルが $15 \sim 60 \mathrm{~nm}$ に相当する範囲で, 両者の間に $I(q) \propto q^{-4}$ という関係が成立することが示された。

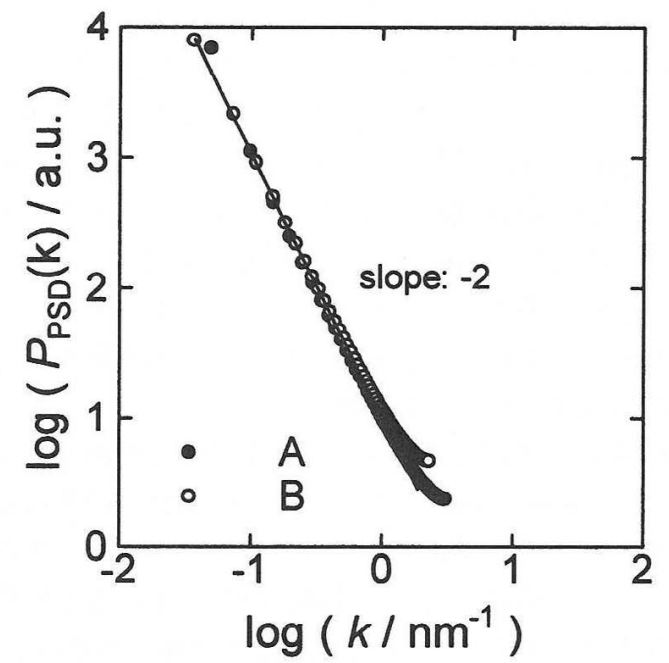

Fig. 5. Double logarithmic plots of surface power spectral density, $P_{\mathrm{PSD}}(k)$, versus absolute value of wave number vector, $k$, calculated from the autocorrelation functions, $g(r)$, in Fig. 4. Legend is the same as shown in Figs. 2 and 4.

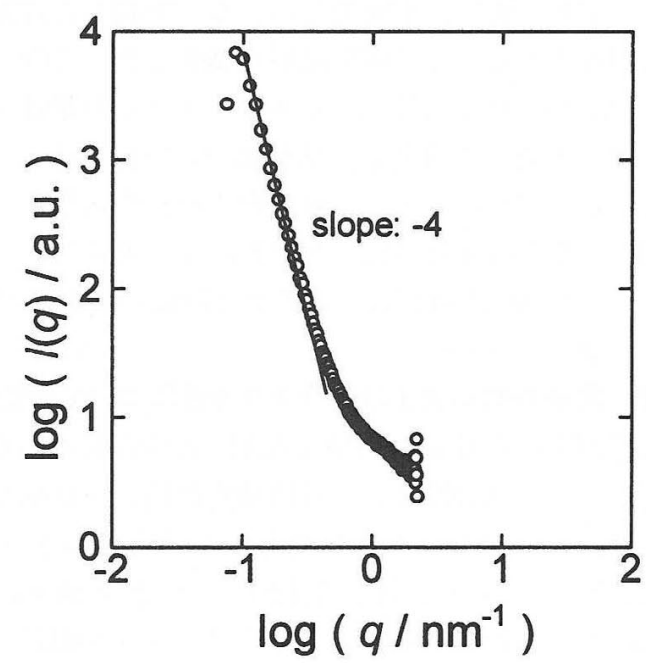

Fig. 6. Double logarithmic plots of scattering intensity, $I(q)$, versus scattering vector, $q$, obtained from SAXS measurement of the pulp fiber sheet.

\section{4 考察 \\ $4 \cdot 1$ セルロース繊維表面の微細構造}

Figs. 2 および 3 で，ミクロフィブリル様微細䋊維の幅 は約 70nm であることが見積もられたが, AFM では探針 の形状が得られる像に大きく反映されることに注意しな ければならない.1) AFM 像に打ける高さはほぼ真の值を表 していることを考え，また微細繊維の断面が円形で近似 できるとすると，これらの像に見られる微細瀻維の直径 は平均で $5.8 \mathrm{~nm}$ になる.この值は透過電子顕微鏡観察で 得られる針葉樹のミクロフィブリル幅 $\left(2 \sim 4 \mathrm{~nm}^{8)}\right)$ にほ ぼ対応している.また Fig. 2では, これらが平行に，一 方向に配向していることから,これらの像に見られる微 細繊維は，針葉樹仮道管の二次壁に由来するミクロフィ ブリルであると考えることができる. ${ }^{8) ま た ~ F i g . ~} 3$ におい て、そのミクロフィブリルの高さが急に減少しているの 
は，画像の中央部で複数重なっていたミクロフィブリル が，画像の左上角では単独で存在していると説明できる.

Figs. 2 および 3 では，ミクロフィブリル上に周期的に 粒状の構造が確認できる。これに関しては，再生セルロ 一スゲルにも同様の構造が認められており，これがゲル生 成過程での再沈殿の際に形成されると予想されている. しかし今回の観察で, この構造が天然セルロースにも確 認されたことから，これがセルロースに本来備わってい る構造に起因することが示唆される.

周期構造の成因については，さまざまな理由が考えら れる.すなわち，(1) セルロースの結晶および非晶領域 に由来する差異，(2) セルロースミクロフィブリルが持 つヘリックス構造, (3) 試料調製の際に水による膨潤・ 収縮を繰り返すことによって生成した座屈, あるいは (4) セルロースミクロフィブリル上を覆うへミセルロースな どの非繊維状物質の存在，などである。しかし，Fig. 3 においては，ミクロフィブリル近傍の基材表面にも粒状 の構造が見られる. 基材上の粒状構造がミクロフィブリ ル上のそれと同じものであるとすると，上記 (1)〜 (3) は 理由として考え難い. 本研究では，水で膨潤した繊維を 基材に吸着させることで観察試料を調製した。この方法 では, 水溶性多糖であるへミセルロースなどの非繊維状 物質が繊維表面から溶出し, 基材表面に付着することが 考えられる。したがって，今回観察された粒状構造の成 因は (4) である可能性が高いと思われる。実際に，へミ セルロースを AFM 観察し, 本研究と同様の粒状構造を 確認した報告 ${ }^{4)}$ がある.

\section{$4 \cdot 2$ 定量的解析およびフラクタル性についての検討}

自己相関関数を Gauss 関数で近似した場合に求められ る相関長 $\xi$ は, 元の像における特徴的な長さを反映して いる. Fig. 4 のプロットAに対して求められた $\xi=63$ $\mathrm{nm}$ およびプロット B に対して求められた $\xi_{1}=49 \mathrm{~nm}$ は, 元画像における粒状構造の大きさやフィブリル幅に対応 していると考えることができる．また，Fig. 2B には比較 的高いフィブリルが周期的に存在するが，Fig. 4B に対し て求められた $\xi_{2}=180 \mathrm{~nm}$ は，このフィブリル間の距離に よく一致する. 以上のことから, 今回求めた相関長は, 元 の AFM 像に存在する特徴を表していることが示された.

Fig. 5 に示される PSD においてべき乗則が成り立ち, その指数が-2であることから，七ルロース繊維の表面構 造は観察範囲において 2 次元的であるということができ る、すなわち，この範囲でセルロース繊維の表面はフラ クタル性を持たないといえる。 また Fig. 6 においても $I(q)$ と $q$ の間にべき乗則が成り立ち，指数は-4になった が，このことは SAXS 測定が Porod 則 ${ }^{10), 11)}$ が適用でき る範囲で行われたことを示している.すなわち，この範 囲において纎維表面は平滑かつ明瞭な境界面をもつこと が示唆される.この場合, 表面の構造を反映する表面フ ラクタル次元 $D_{s}$ は, ベきの指数 $\alpha$ と $D_{s}=6-\alpha$ の関係に ある. ${ }^{12)}$ したがって, Porod 則が成立している場合では $D_{s}$
$=2$, つまり表面構造は 2 次元的であることを意味する. 両測定が，ほぼ同じ空間スケールにおいて同様の結果を 示したことは興味深い.

以上のことから, AFM 像の Fourier 変換によって得ら れたパワースペクトルと SAXS 測定によって得られた散 乱強度は, 本実験で用いたパルプ㵶維の表面はフラクタ ル構造をもたないことを示しているが，両測定は表面の フラクタル性に関して共に同じ結果を与え得ることが判 明した. 従来の光を試料に透過させる散乱法では表面の 散乱像は得られなかったが, AFM 像の Fourier 変換によ って得られるパワースペクトルは表面の散乱像に対応さ せて考えることができるといえる。

\section{5 結}

AFM 像の自己相関関数を Fourier 変換することにより 得られた表面の凹凸に関するパワースペクトルは, 従来 の散乱測定より得られる波数空間像に対応していること が示唆された。この手法によって得られるセルロース䋊 維表面のナノメータースケールでの微細構造は, 繊維の 表面特性や紙の繊維間結合を考えるうえでの基礎的な知 見になるものと思われる。

なお，本研究は筆頭著者に対する科学研究費補助金 (奨励研究 (A)，No. 11760123）の一部によって行われ たことを記し，深謝いたします。

\section{参 考 文 献}

1) S. J. Hanley and D. G. Gray, Holzforschung, 48, 29 (1994).

2 ) S. J. Hanley, J.-F. Revol, L. Godbout and D. G. Gray, Cellulose, 4, 209 (1997).

3 ) S. J. Hanley and D. G. Gray, J. Pulp Pap. Sci., 25, 196 (1999).

4) Å. Henriksson and P. Gatenholm, Holzforschung, 55, 494 (2001).

5) H. Tanaka, T. Hayashi and T. Nishi, J. Appl. Phys., 59, 3627 (1986)，田中 肇，西 敏夫，日本レオロジー学会誌，15, 5 (1987).

6) H. Hayashi, F. Hamada, S. Suehiro, N. Masaki, T. Ogawa and H. Miyaji, J. Appl. Cryst., 21, 330 (1988).

7 ) A. Suzuki, M. Yamazaki, Y. Kobiki and H. Suzuki, Macromolecules, 30, 2350 (1997).

8）島地謙, 佐伯 浩, 原田 浩, 塩倉高義, 石田茂雄, 重松頼生, 須藤彰司, “木材の構造”, $\mathrm{V}$ 章 (1985) 文永堂 出版.

9) 小野博文, Cellulose Commun., 6, 101 (1999).

10) G. Porod, Kolloid-Z., 124, 83 (1951).

11) J. S. Lin, M.-Y. Tang and J. F. Fellers, "The Structure of Cellulose : characterization of the solid states", R. H. Atalla, Ed., Chap.14 (1987) American Chemical Society, Washington, DC.

12) P. W. Schmidt, "The Fractal Approach to Heterogeneous Chemistry-Surfaces, Colloids, Polymers”, D. Avinir, Ed., Chap. 2.2 (1989) John Wiley \& Sons, Chichester. 